\title{
Non-amyloid fibrillary glomerulopathy
}

INSERM

\section{Source}

INSERM. (1999). Orphanet: an online rare disease and orphan drug data base. Nonamyloid fibrillary glomerulopathy. ORPHA:97566

Non-amyloid fibrillary glomerulopathy (non-amyloid FGP) is a rare cause of glomerulonephritis (GN) characterized by glomerular accumulation of non-amyloid fibrils in the mesangium and the glomerular (and rarely tubular) basement membrane, that mainly presents with renal insufficiency, micro-hematuria and nephrotic range proteinuria. Non-amyloid FGP and immunotactoid glomerulopathy (ITG, see this term) are often grouped together as pathogenetically related diseases. 